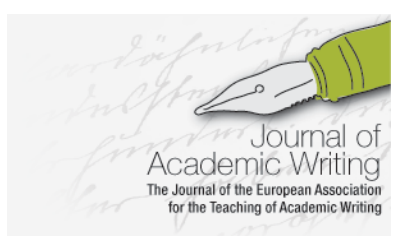

Journal of Academic Writing Vol. 8 No 2 Winter 2018, pages 225-228 http://dx.doi.org/10.18552/joaw.v8i2.439

\title{
Embedding Writing Support Within a Psychology Academic Skills Module: A Case Study
}

Alana I. James

University of Reading, UK ${ }^{1}$

\begin{abstract}
A Psychology academic skills module and challenges in its delivery are outlined. Adaptations described include embedding specialist support for the teaching of academic writing and linking content to assessments and careers. Increased student satisfaction and qualitative feedback indicated that changes were beneficial. The need for further evaluation is discussed.
\end{abstract}

\section{The Module}

A review was conducted of a two-term academic skills module for first-year Psychology undergraduates. Academic writing skills covered included finding sources, referencing, plagiarism, essay structuring, and critical analysis. Other skills taught included understanding of research, presentation skills, and revision strategies. Attendance was compulsory for singlehonours students, and expected for joint-honours/visiting/Liberal Arts students; cohort size was approximately $180-200$.

Student satisfaction with the module was typically varied; some were highly appreciative, some found parts of the content useful, and others felt that the training was not necessary. Further, students' engagement in lectures appeared to decrease over each term.

Several challenges were identified, including:

- Content was delivered by Psychology-specific lecturers, who often changed, and were not experts in the teaching of academic writing and other skills.

- Delivery was via weekly one-hour lectures, due to practical restrictions, with few in-class opportunities for students to practice skills.

- An aim was for content to support students in completing assessments in other modules, but students indicated that they found the order of content confusing and wanted more career-related training.

- Pitching content at an appropriate level was difficult due to students' varying experience of scientific writing. This reflected general diversity in UK Psychology students' pre-tertiary backgrounds (Trapp et al. 2011: 11); a qualification in Psychology, or a cognate subject, is not typically required for degree entry. Additionally, entry students commonly do not conceptualise Psychology as a science (Reddy and Lantz 2010: 73-75), meaning that some do not expect scientific writing skills to be required.

\footnotetext{
${ }^{1}$ At the time that this case study was conducted, the author was affiliated with Royal Holloway, University of London, UK.
} 


\section{Adaptations}

Changes instigated to address these challenges are outlined below.

\section{4/15 onwards:}

i. Co-teaching with library staff - lectures on finding sources, referencing, and using electronic reference systems were developed and delivered in partnership with university library staff. This capitalised upon professional services' specialist knowledge, and aimed to increase students' awareness of library writing support.

ii. Interactive lectures - to enhance student engagement active learning was emphasised via class activities (see for example Prince 2004: 223). For example, quiz questions, use of online response systems, and hands-on tasks reviewing writing examples.

\section{5/16 onwards:}

iii. Grouping of academic skills - to make the rationale for content order clearer lectures were grouped into thematic areas: core writing skills; advanced writing skills; employability-related skills; exam skills; research skills. Separating out core and advanced writing skills aimed to signal to students with existing experience of scientific writing which content was pitched at a higher level.

iv. Linking of writing skills to assessments - the writing skills required for each assessment in other modules in term one were established and mapped on to the writing skills lectures. The assessment order was reviewed with the department's director of teaching to ensure that the required writing skills gradually increased in complexity. Links with upcoming assessments were clearly signposted to students at the start of each lecture.

v. Emphasis upon career development - lectures on employability were developed and delivered in partnership with the university psychology careers advisor. In writing skills lectures, an emphasis was placed upon how skills would be useful across students' degree and careers.

\section{6/17 onwards:}

vi. Co-teaching with academic skills staff - lectures on core and advanced writing skills were re-developed and delivered in partnership with staff from the university centre for academic skills development.

\section{Outcomes}

In 2013/14 students were asked to what extent they agreed with the statement: 'Overall this was a good course'; for the term focusing upon writing skills $40 \%$ agreed/strongly agreed (total $\mathrm{n}=110$ ). The university feedback form statement subsequently changed to: 'Overall, I am satisfied with this course'; $27.8 \%$ agreed/strongly agreed in 2014/15 (total $n=144$ ), which rose to $62.9 \%$ in $2015 / 16$ (total $n=116$ ) and $72.1 \%$ in $2016 / 17$ (total $n=104$ ).

Qualitative responses in 2015/16 and 2016/17 were generally more positive, and particularly indicated that students perceived how lectures linked to their assessments and general development, for example, 'Some useful and essential skills + advice to help improve studying + coursework'. Engagement within lectures and the proportion of students accessing writing support from the library and centre for academic skills both appeared to increase. Feedback from students' personal tutors also indicated that the changes were beneficial.

However, impact upon performance was not evaluated; no assessments were set within the module, and it was not possible to control for other factors affecting written work on other modules. In the future, to directly evaluate the module's impact, writing skills could be assessed at the start of the academic year, and at the ends of terms one and two, for example through formative written work or a skills test. 


\section{Reflections}

This case study provides an example of how teaching practice on an academic skills module was adapted over several years. The impact of changes was monitored using module evaluation forms, but the utility of this data is limited as they are not a measure of actual performance or understanding and were not completed by the full cohort.

A particular challenge in evaluating the changes made to this Psychology skills module was its stand-alone nature. There were no assessments within the module upon which performance could be compared across or within cohorts, and many factors affecting the assessments on other modules were outside of control, for example, type of essay question set, or any additional support provided. Integrating formative writing tasks within the module could overcome this, but these would need to be designed to be practical. For example, either fitting within class time or fitting around students' existing assessment load, and requiring limited marking/feedback time. This demonstrates the difficulties in balancing the need for effective evaluation methods with the realities of routine teaching practice.

Partnership working between subject specialists and academic writing specialists could help to design a practical way of evaluating the effectiveness of module changes in the future. A key focus of the adaptations was the embedding of specialist support from professional university services. Academics and professional staff worked together to create content which developed students' writing skills whilst demonstrating the importance of these skills in psychological careers. Co-developing a practical evaluation approach could be the next step. 


\section{References}

Prince, M. (2004) 'Does Active Learning Work? A Review of the Research'. Journal of Engineering Education 93 (3), 223-231

Reddy, P. and Lantz, C. (2010) 'Myths, Maths and Madness: Misconceptions around Psychology'. in Teaching Psychology in Higher Education. ed. by Upton, D. and Trapp, A. Oxford: Blackwell Publishing, 54-81

Trapp, A., Banister, P., Ellis, J., Latto, R., Miell, D., and Upton, D. (2011) The Future of Undergraduate Psychology in the United Kingdom. York: The Higher Education Academy Psychology Network. [online] available from

<https://www.heacademy.ac.uk/knowledge-hub/future-undergraduate-psychologyunited-kingdom> [18 October 2018] 